\title{
Colistin and tigecycline for management of external ventricular device-related ventriculitis due to multidrug-resistant Acinetobacter baumannii
}

Gentle Sunder Shrestha, Sushil Tamang, Hem Raj Paneru, Pramesh Sunder Shrestha, Niraj Keyal, Subhash Prasad Acharya, Moda Nath Marhatta, Sushil Shilpakar ${ }^{1}$

Department of Anaesthesiology, Institute of Medicine, Tribhuvan University Teaching Hospital, ${ }^{1}$ Department of Surgery, Neurosurgery Unit, Tribhuvan University Teaching Hospital, Kathmandu, Nepal

\section{ABSTRACT}

Acinetobacter baumannii is an important cause of nosocomial ventriculitis associated with external ventricular device (EVD). It is frequently multidrug resistant (MDR), carries a poor outcome, and is difficult to treat. We report a case of MDR Acinetobacter ventriculitis treated with intravenous and intraventricular colistin together with intravenous tigecycline. The patient developed nephrotoxicity and poor neurological outcome despite microbiological cure. Careful implementation of bundle of measures to minimize EVD-associated ventriculitis is valuable.

Key words: Acinetobacter baumannii, colistin, intraventricular, multidrug resistant, tigecycline, ventriculitis

\section{Introduction}

External ventricular device (EVD) is useful in monitoring intracranial pressure (ICP) in patients with severe traumatic brain injury and abnormal computed tomography (CT) scan of the head. ${ }^{[1]}$ However, the presence of EVD is a well-known risk factor for infection of central nervous system (CNS) with the incidence of $1-18 \% .{ }^{[2]}$ Acinetobacter baumannii has emerged as an important nosocomial infectious agent due to its ability to tolerate desiccation and to accumulate diverse mechanisms of resistance..$^{[3]}$ Acinetobacter meningitis is associated with high mortality ranging from $15 \%$ to $71 \%{ }^{[4]}$

Successful treatment with intravenous and intrathecal/ intraventricular colistin has been reported. ${ }^{[2,3,5]}$ There are few reports of successful use of tigecycline for

Address for correspondence:

Dr. Gentle Sunder Shrestha, Department of Anaesthesiology, Institute of Medicine, Tribhuvan University Teaching Hospital, Maharajgunj, Kathmandu, Nepal.

E-mail: gentlesunder@hotmail.com

\begin{tabular}{|l|l|}
\hline \multicolumn{2}{|c|}{ Access this article online } \\
\hline Quick Response Code: & Website: \\
\hline & www.ruralneuropractice.com \\
\cline { 2 - 2 } & \\
\hline & \\
&
\end{tabular}

treatment of multidrug resistant (MDR) A. baumannii meningitis. ${ }^{[6]}$ Colistin is potentially nephrotoxic, which increases with higher cumulative dose and in patients with preexisting renal impairment. ${ }^{[7]}$ Here, we report a successful microbiological cure of EVD-associated MDR Acinetobacter ventriculitis using intravenous and intraventricular colistin together with intravenous tigecycline. However, the patient had progressive deterioration in neurological and renal function.

\section{Case Report}

A 75-year-old patient presented with the history of decreased level of consciousness and weakness in left half of the body following trivial fall. CT scan of the head revealed small right subdural hematoma with frontal contusion. Glasgow Coma Scale (GCS) was $7\left(\mathrm{E}_{1} \mathrm{~V}_{1} \mathrm{M}_{5}\right)$ with bilateral equal and reacting pupils. Patient was planned for conservative management. He was intubated and put on mechanical ventilation for poor GCS. EVD

This is an open access article distributed under the terms of the Creative Commons Attribution-NonCommercial-ShareAlike 3.0 License, which allows others to remix, tweak, and build upon the work non-commercially, as long as the author is credited and the new creations are licensed under the identical terms.

For reprints contact: reprints@medknow.com

How to cite this article: Shrestha GS, Tamang S, Paneru HR, Shrestha PS, Keyal N, Acharya SP, et al. Colistin and tigecycline for management of external ventricular device-related ventriculitis due to multidrug-resistant Acinetobacter baumannii. J Neurosci Rural Pract 2016;7:450-2. 
was placed for monitoring of ICP. Patient was on treatment with ceftriaxone $1 \mathrm{~g} 12$ hourly for aspiration pneumonia. ICP was maintained at $10-15 \mathrm{mmHg}$.

After 3 days, patient had progressive drop in GCS to $4\left(E_{1} M_{3} V_{t}\right)$. Repeat $C T$ head revealed no new findings. EVD was in proper position and functioning. On the day 4 , he developed high-grade fever (up to $103^{\circ} \mathrm{F}$ ). EVD associated ventriculitis was suspected. Analysis of cerebrospinal fluid (CSF) sample revealed total count of 630 cells $/ \mathrm{mm}^{3}$ with $90 \%$ polymorphs with sugar of $20 \mathrm{mg} / \mathrm{dL}$ and protein of $180 \mathrm{mg} / \mathrm{dL}$. Corresponding blood sugar was $146 \mathrm{mg} / \mathrm{dL}$. His serum creatinine level was $1.5 \mathrm{mg} / \mathrm{dL}$. Antibiotics were empirically upgraded to vancomycin and ceftazidime. CSF sample was sent for culture and sensitivity which revealed A. baumannii sensitive only to colistin and tigecycline and resistant to all other antibiotics including carbapenems. Vancomycin and ceftazidime were stopped. Infected EVD was removed and a new ventricular drain was placed on opposite side.

Intravenous colistin was started at the dose of 2 million IU 8 hourly together with 200,000 IU through intraventricular route daily. Tigecycline was administered intravenously at a loading dose of $100 \mathrm{mg}$ followed by $50 \mathrm{mg}$ twice daily. CSF culture after 3 days of starting colistin and tigecycline was negative with decrease in cell count to 25 cells $/ \mathrm{mm}^{3}$. Subsequent two consecutive CSF cultures done on alternate days were negative. The CSF analysis done on the day 7 of starting of colistin was normal. Patient was afebrile from the day 3. Intraventricular colistin was discontinued on the day 8 . However, there was progressive decline in GCS to $2\left(E_{1} M_{1} V_{t}\right)$. Serum creatinine level was followed daily. Due to progressive worsening of renal function, intravenous dose of colistin was decreased to 2 million IU 24 hourly on the day 5 when creatinine reached $4 \mathrm{mg} / \mathrm{dL}$. Intravenous colistin and tigecycline was continued for 14 days when the family members of patient decided to withdraw the support due to anticipated poor neurological outcome despite microbiological cure of ventriculitis.

\section{Discussion}

Acinetobacter spp. possess an impressive armamentarium of resistance mechanisms rendering it resistant to almost all commercially available antibiotics. ${ }^{[4]}$ Colistin is widely used for the treatment of infections by MDR Gram-negative rods ${ }^{[8]}$ However, intravenous administration of colistin is associated with a very low CNS transfer of only around $5 \%$. A concomitant intraventricular administration is required for treatment of severe ventriculitis in patients with EVD. The ideal dose, duration, and route of treatment are controversial. ${ }^{[2]}$ The literature review suggests a minimum intrathecal dose of 125,000 IU daily as suggested by the guidelines of Infectious Disease Society of America ${ }^{[9]}$ and may possibly increase to $250,000 \mathrm{IU}$ daily. Intraventricular route was safe, effective, and well-tolerated..$^{[2]}$ Hence, we administered 200,000 IU daily. Duration of intraventricular treatment $<7$ days is possibly associated with higher mortality. ${ }^{[2]}$ In our case, it was administered for 8 days. Combination of intraventricular and intravenous therapy was chosen as intraventricular therapy alone is not sufficient to treat EVD-related ventriculitis due to MDR Gram-negative pathogen. ${ }^{[2]}$

Nephrotoxicity attributable to colistin therapy ranges between $0 \%$ and $53.5 \%$. It is higher in patients with baseline renal dysfunction. Kidney injury is related to total cumulative dose and duration of therapy. As in our patient, older and more severely ill patients are at higher risk for nephrotoxicity, and it independently predicts higher mortality. ${ }^{[7]}$ Serum creatinine level was measured daily. Dose of colistin was adjusted with the renal function.

Tigecycline has demonstrated good in vitro activity against MDR A. baumannii, but current evidence does not support its use as monotherapy. Hence, tigecycline was used as a component of multidrug and multi-route therapy for our patient. Despite successful microbiological clearance, patient had poor neurological outcome. The bundle of measures such as education of Intensive Care Unit personnel, meticulous intraventricular catheter handling, and CSF sampling only when clinically necessary routine replacement of drainage catheter on the $7^{\text {th }}$ day is associated with significantly decreased incidence of EVD-associated infection. ${ }^{[10]}$ It should be considered in all patients with EVD.

\section{Conclusion}

EVD-associated MDR Acinetobacter infection is associated with poor outcome. Intraventricular and intravenous colistin combined with intravenous tigecycline may be effective in microbiological clearance of bacteria. Bundle of measures should be implemented in all patients with EVD and at risk of MDR infection to prevent the disastrous outcomes.

\section{Financial support and sponsorship Nil.}




\section{Conflicts of interest}

There are no conflicts of interest.

\section{References}

1. Brain Trauma Foundation, American Association of Neurological Surgeons (AANS), Congress of Neurological Surgeons (CNS), AANS/ CNS Joint Section on Neurotrauma and Critical Care. Guidelines for the management of severe traumatic brain injury. VII. Intracranial pressure monitoring technology. J Neurotrauma 2007;24 Suppl 1:S45-54.

2. Bargiacchi O, Rossati A, Car P, Brustia D, Brondolo R, Rosa F, et al. Intrathecal/intraventricular colistin in external ventricular device-related infections by multi-drug resistant Gram negative bacteria: Case reports and review. Infection 2014;42:801-9.

3. Cascio A, Conti A, Sinardi L, Iaria C, Angileri FF, Stassi G, et al. Post-neurosurgical multidrug-resistant Acinetobacter baumannii meningitis successfully treated with intrathecal colistin. A new case and a systematic review of the literature. Int J Infect Dis 2010;14:e572-9.

4. Kim BN, Peleg AY, Lodise TP, Lipman J, Li J, Nation R, et al. Management of meningitis due to antibiotic-resistant Acinetobacter species. Lancet Infect Dis 2009;9:245-55.

5. Katragkou A, Roilides E. Successful treatment of multidrug-resistant Acinetobacter baumannii central nervous system infections with colistin. J Clin Microbiol 2005;43:4916-7.

6. Gordon NC, Wareham DW. A review of clinical and microbiological outcomes following treatment of infections involving multidrug-resistant Acinetobacter baumannii with tigecycline. J Antimicrob Chemother 2009;63:775-80.

7. Spapen H, Jacobs R, Van Gorp V, Troubleyn J, Honoré PM. Renal and neurological side effects of colistin in critically ill patients. Ann Intensive Care 2011;1:14.

8. Falagas ME, Kasiakou SK. Colistin: The revival of polymyxins for the management of multidrug-resistant gram-negative bacterial infections. Clin Infect Dis 2005;40:1333-41.

9. Tunkel AR, Hartman BJ, Kaplan SL, Kaufman BA, Roos KL, Scheld WM, et al. Practice guidelines for the management of bacterial meningitis. Clin Infect Dis 2004;39:1267-84.

10. Chatzi M, Karvouniaris M, Makris D, Tsimitrea E, Gatos C, Tasiou A, et al. Bundle of measures for external cerebral ventricular drainage-associated ventriculitis. Crit Care Med 2014;42:66-73. 